\title{
A six-component model for assessing procedural fairness in the Intergovernmental Panel on Climate Change (IPCC)
}

\author{
Chukwumerije Okereke ${ }^{1}$ (D)
}

Received: 26 April 2017 / Accepted: 20 October 2017/Published online: 13 November 2017

(C) The Author(s) 2017. This article is an open access publication

\begin{abstract}
This article provides an analysis of the Intergovernmental Panel on Climate Change (IPCC) focusing on procedural justice. I demonstrate how, to what end, and with what effects questions of justice and procedural fairness matter in the IPCC work. Then, with the aim to advance crtical research, policy and practice on this important subject, I draw on scholarship from social psychology and legal procedures along with socio-political literature on the IPCC, to develop a six-component framework for evaluating procedural fairness in the IPCC. These include the following: (1) formal rules about representation and participation; (2) formal rules about governance and management structure; (3) formal rules relating to decision-making processes; (4) formal rules on fair treatment of authors; (5) informal quality of decision-making rules by authorities; and (6) informal quality of the interactional environment. Systematic assessment is required to validate the six-component procedural justice model and to reveal existing strengths of, and areas for improvements for, the IPCC procedure.
\end{abstract}

\section{Introduction}

The Intergovernmental Panel on Climate Change (IPCC) is a unique international scientific organization which plays a pivotal role in deciding international and national climate policies. Reflecting its preeminent authority to frame climate change and how it is tackled (or not), the IPCC has attracted plenty of close attention from both academic and policy commentators, with questions of participation, integrity of procedures, trust, legitimacy and accountability receiving considerable attention (Beck 2012; Biermann and Gupta 2011; Bjurström and Polk 2011a, 2011b; Corbera et al. 2016; Hughes 2015; Hulme and Mahony 2010; Ford et al. 2012; Vardy et al. 2017).

Critical IPCC scholarship from science and technology studies (STS), political science, geography and sociology highlight among other issues, geographical imbalance of authors in favour of developed countries (Bjurström and Polk 2011a; Pasgaard et al. 2015), the dominance of elitist epistemology and positivist framing (Hulme and Mahony 2010; Obermeister

Chukwumerije Okereke

c.okereke@ reading.ac.uk

1 University of Reading, Reading, UK 
2017), gender imbalance of authors (Corbera et al. 2016), problems with the rules of procedure over consensus, uncertainty, and the use of grey literature (Yohe and Oppenheimer 2011; Mach et al. 2017), the marginalization of indigenous knowledge (Ford et al. 2012, 2016), and the superior role of Western institutions and networks in the IPCC assessment reports (Corbera et al. 2016). These issues and several of the above-cited literature raise salient questions about the procedural fairness of the IPCC process, especially in the context of North-South climate justice. It is curious, therefore, that there is hardly any literature that has analysed the IPCC explicitly and distinctly through the lens of procedural justice, defined as the fairness, or at least perceived fairness, of the structures and procedures used in decision-making (Rawls 1971).

Furthermore, it is well-known that developing countries have, since the creation of the IPCC in 1989, raised justice-related concerns expressed mostly in their complaint about lack of opportunity and capacity to facilitate their effective representation and contribution (cf. Agrawala 1998a, 1998b; Bodansky 1993). For its part, the IPCC has long recognized and sought to address issues of unfairness in their process even though these are often cast in the language of legitimacy and transparency rather than procedural justice. These have included notable efforts to increase the representation of authors from developing countries, balancing the constitution of Coordinating Lead Authors, expanding the work on adaptation, and widening the remit of the chapters to deal with equity and sustainable development (Najam et al. 2003; Siebenhüner 2002; Vardy et al. 2017). Despite notable progress, however, there remains a strong feeling among developing countries and critical scholarship that the IPCC process and knowledge are skewed in favour of the North and that more can be done to enhance the involvement and contribution of developing countries (Pasgaard et al. 2015). Some scholars have gone further by calling for the IPCC to be radically reformed or even disbanded (Brown and Havstad 2017; Devès et al. 2017; Hulme et al. 2010; Stocker et al. 2014).

While existing scholarship has done a lot to indicate the various ways in which the IPCC process raises questions of fairness, the lack of explicit attention to procedural justice means that there is still no clear framework for understanding and analysing procedural fairness in the IPCC. This represents a major gap. Critical commentary on the IPCC and calls for reforms which emanate from casual observation and socio-political analysis have important intellectual and practical utility. However, without a clear framework for conceptualizing and evaluating the procedural justice of the IPCC, it will be difficult to tackle the problem systematically and to measure progress. With its mandate to produce comprehensive, objective and balanced reviews that are politically relevant, the IPCC has to reconcile the requirement of scientific integrity with political demands for fairness, geopolitical representation and public accountability. The challenge is, therefore, to explicate how and why justice matters, as well as an ideal of procedural fairness that enhances the ability of the IPCC to achieve these multiple, complex and potentially conflicting objectives.

With the aim to advance critical research, policy and practice on this important subject, I draw on scholarship from social psychology and legal procedures to construct a unique analytical model for evaluating procedural fairness in the IPCC. Conceptual mapping and categorization is vital for thinking more concretely about the various domains where rules of procedure and practice can change to promote procedural fairness. As the sixth IPCC assessment cycle gets underway, it is vital to continue to explore how best to analyse and strengthen procedural fairness in the IPCC with a view to enhancing the organization's ability to meet its objectives of producing sound, balanced and comprehensive reports that can drive effective and equitable global response to climate change.

The rest of the paper develops as follows. In the next section, I review the basis for possible sentiment against procedural justice in the IPCC and I demonstrate how, to what end, and with 
what effects questions of fairness and procedural justice matter in the IPCC work. In Section 3, I provide a quick overview of the IPCC indicating its governing structure and work process. In Section 4, I combine scholarship from psychology, conflict management and legal procedures with IPCC literature, to develop a six-component framework for assessing and improving procedural justice in the IPCC. In the final selection section, I provide a brief discussion of the framework before drawing some concluding remarks.

\section{Procedural justice and the IPCC}

One reason for the near total silence on procedural justice by IPCC literature may lie in the implicit notion that it is inappropriate to apply the concept of justice to the IPCC since there are no direct distributional consequences of IPCC reports. Obviously, in the United Nations Framework Convention (UNFCCC) or any other substantive governance initiative, one could explore procedural justice in terms of the outcome because there are clear distributive effects, such as who has to reduce emissions, and how an unjust process might create or exacerbate existing unfairness (Grasso and Sacchi 2015; Tomlinson 2015; Okereke 2008, 2010). Since it seems that an IPCC report cannot be just or unjust in this manner, and perhaps only scientifically accurate or inaccurate, some might suggest that the emphasis of IPCC procedure should not be on justice, with its strong moral and ethical connotations, but rather on ensuring rigorous and comprehensive scientific review and selecting authors and input materials that can help to achieve such an outcome. In this frame, it could even be suggested-some developed country scientists have in fact voiced this view - that a concern for justice (for example, regarding an equitable North-South representation) could undermine the goal of producing robust IPCC science.

This objection is, however, largely misplaced. There are at least four grounds to demonstrate that a concern for procedural justice in the IPCC is not only valid but in fact urgently warranted. First, as already indicated, it is now abundantly evident from existing literature that while the IPCC reports are not governance instruments in themselves, per se, they have significant ability to influence climate policy in justice-enhancing or constraining ways (Corbera et al. 2016; Ford et al. 2012, 2016; Hughes 2015; Hulme and Mahony 2010). For example, Biermann (2001) suggests that IPCC reports affect national policy, constructions of climate equity and donor-driven research in India. Occupying its commanding position as the world's most authoritative voice on climate science, the IPCC has important "symbolic power" (Hughes 2015) and far-reaching influence in shaping the tenor, urgency and political decisions of climate change. In doing so, the IPCC can frame-(indeed has often framed) - climate science and policy in ways that provide legitimacy for one approach over competing alternatives (Fløttum et al. 2016; Ford et al. 2016; Hughes 2015). For example, the IPCC has been criticized for promoting a utilitarian economic frame for climate policy with its emphasis on cost-benefit analyses and underappreciation of ethical considerations (Bjurström and Polk 2011a, b). More recently, in the AR5, the IPCC appears to have made a concerted attempt to frame climate change in terms of risk rather than, for example, as a challenge warranting fundamental changes in the values and structure of societies (Fløttum et al. 2016). Furthermore, while the IPCC strives hard to stick to its mandate to provide policy-relevant information without being policy prescriptive, they have, in the past, perhaps unavoidably, made pronouncements on very controversial social and political issues such as luxury emissions, historical responsibility for emissions, value of life, discount rates and division of 
country groups some of which have been viewed as validating worldviews that promote climate policies that marginalize poor countries (Khanna and Chapman 1996; Liu et al. 2014).

Second, a strong body of STS literature has comprehensively refuted a "black box" imagery of the IPCC that implies it neatly demarcates between value-free science and politics (Bjurström and Polk 2011b; Mach et al. 2017; Pasgaard et al. 2015). Rather, it has been shown that in functioning simultaneously as a scientific and an intergovernmental body, the IPCC is a boundary or hybrid organization whose constructions of climate change are shaped by both scientific and political interests (Beck 2011; Hughes 2015; Siebenhüner 2002; ; Skodvin 2000). It is the abiding presence of these political interests and calculus that raises the stake for procedural justice. In recognition of its unique position, the IPCC goes to considerable length to ensure the transparency of its process. The IPCC generally avoids the language of justice and fairness but rather prefers to justify its rules of procedural as well as the drive to increase the participation of authors from developing countries in terms of bolstering its credibility and legitimacy. However, as Bradford et al. (2014), Biermann and Gupta (2011), Levi and Sacks (2009) and Murphy (2005) among others have all noted, the legitimacy of, and trust in, institutions are both strongly linked to perceptions of procedural fairness.

Third, scholarship has shown that beyond being a boundary organization, the IPCC process is deeply sociological and deliberative (Beck 2012; Hajer 2012; Hughes 2015; Hughes and Paterson 2017). Accordingly, it incorporates all the "messiness" and relational aspects of politics, power, authority and knowledge construction that characterize normal social interactions. This helps to explain why even with the best effort at scientific objectivity, the IPCC report still demonstrates a bias towards powerful political interests and epistemologies (Ford et al. 2012; Hulme and Mahony 2010; Pasgaard et al. 2015). Hence, in facilitating a process where a diverse range of knowledge claims and views are effectively represented and considered, explicit attention to procedural fairness could mitigate or counter-balance the inevitable influences of political interests and epistemologies. In doing so, procedural fairness can help to bring about the outcome of good science, understood in terms of credible, relevant, comprehensive, and balanced assessment - all of which are objectives explicitly embraced by the IPCC. Moreover, plenty of literature (Bradford et al. 2014; De Cremer and Tyler 2005; Tyler and Blader 2000, 2003; Yang et al. 2009) has demonstrated that procedural fairness promotes trust and cooperation which enhances efficiency and effectiveness in group work - all these are outcomes that many would readily embrace as desirable for the IPCC.

Fourth, and lastly, even if a report or deliberative process is inconsequential regarding its governance outcome or impact on people, an argument for procedural fairness could still be made on an intuitive basis. This accords with a vast literature in ethics and psychology which asserts that procedural fairness has independent, intrinsic value that is not linked to any influence over decisions made (Rawls 1971; Alexander and Ruderman 1987; Tyler and Caine 1981; Tyler and Blader 2000). In fact, a significant amount of procedural justice literature from psychology and conflict management distinguishes between the quest for procedural justice in an allocation or decision making context from concerns for inter-personal aspects of procedural justice, "which arise because procedures are settings within which people [and nations] are involved in social interaction with one another" (Tyler and Blader 2003: 350).

\section{Structure and function of the IPCC}

Established in 1988 by the World Meteorological Organization (WMO) and the United Nations Environment Programme (UNEP), the IPCC is the international body for assessing 
the science related to climate change. The IPCC does not conduct its own scientific studies. Its mandate is to produce scientifically rigorous, comprehensive, objective and balanced reviews that are politically relevant but not politically prescriptive. The IPCC work relies on hundreds of scientists who are nominated by their governments and by observer organizations (see Fig. 1 for the IPCC process). Scientists can also be nominated by the IPCC Bureau on the basis of their own work. Since its establishment, the IPCC has published five assessment reports, roughly every five years. The IPCC also publishes a report on National Greenhouse Gas Inventories as well as "Special Reports" that provide an in-depth assessment of a specific issue. Examples include emission scenarios and extreme events. The IPCC is currently in its Sixth Assessment cycle, which will be finalized in 2021.

The IPCC is currently organized in three Working Groups (see Fig. 2). WG I deals with the physical science of climate change. WG II deals with climate change impact, vulnerability and

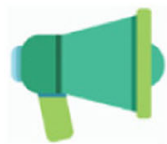

Scoping

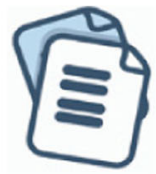

Approval of Outline

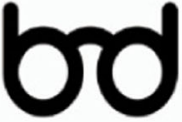

Nomination of authors

The outline is drafted and developed by experts nominated by governments and observer organizations

The Panel then approves the outline
Governments and observer organizations nominate experts as authors

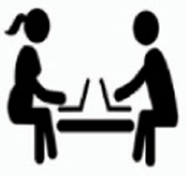

Government and Expert Review - 2nd Order Draft

The 2nd draft of the report and 1st draft of the Summary for Policymakers (SPM) is reviewed by governments and experts

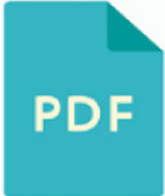

Final draft report and SPM

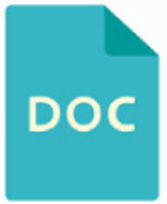

Expert Review 1 st Order Draft

Authors prepare a 1 st draft which is reviewed by experts

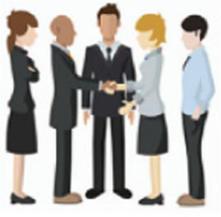

Selection of authors
Bureaux select authors

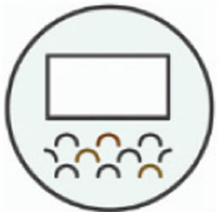

Approval \& acceptance of report

Government review of final draft SPM

Governments review the final draft SPM in preparation for its approval
Working Group/Panel approves SPMs and accepts reports are sent to governments of the report and SPM which

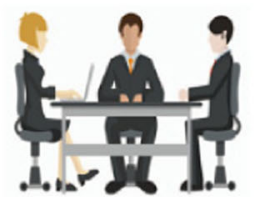




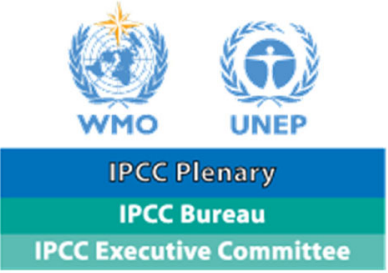

\section{IPCC Secretariat}

PCC Executive Committee
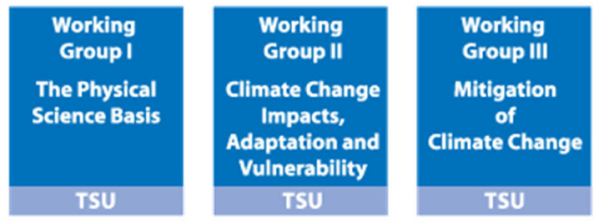

Task Force

on

National

Greenhouse

Gas

Inventories

TSU

Authors, Contributors, Reviewers

Fig. 2 Governance structure of the IPCC (www.ipcc.com)

adaptation. WG 3 deals with climate mitigation and is often also called the policy working group. There is also a Task Force on National Greenhouse Gas Inventories. The three working groups and the task force are each assisted by a dedicated Technical Support Unit (TSU), which serves as the "home" of the Working Group. In the past, the TSU has been hosted and financially supported by the government of the developed country Co-Chair of each Working Group/Task Force. The IPCC has a secretariat located within the WMO in Geneva, which supports the work of the body.

The IPCC Bureau comprises the IPCC Chair, the IPCC Vice-Chairs, the Co-Chairs and Vice-Chairs of the Working Groups and the Co-Chairs of the Task Force. The IPCC Bureau is chaired by the IPCC Chair. The purpose of the Bureau is to guide the Panel on the scientific and technical aspects of its work and to offer advice on related management and strategic issues. Following a recommendation from the independent InterAcademy Council (IAC) in 2010, an IPCC Executive committee was created to "strengthen and facilitate timely and effective implementation of the IPCC programme of work, strengthen coordination between Working Groups and Task Forces and to address urgent issues that require prompt attention by the IPCC between Panel sessions." Major decisions of the IPCC are taken by the Panel in plenary meetings involving government representatives for all member countries.Starting out with relatively few formalized rules in 1988, the IPCC has gone through three major revisions of their rules of procedure, in 1993, 1999 and 2010. The IPCC avers repeately on thier website and numerous policy papers that the guidelines on procedure form an important basis for its work on enhancing legitimacy, participation and the quality of its reports. Rules of procedures are critical for the governance of the expert panels since they specify a variety of methods and steps to ensure that its reports include the best available scientific knowledge and that they represent this knowledge fairly and accurately. They also define how expert authors and reviewers from around the world are to be recruited, and the method for integrating governmental and non-governmental experts into the review processes.

The IPCC has long recognized and sought to address issues of unfairness in their process even though these are often cast in the language of legitimacy and transparency rather than procedural justice. The IPCC has, for example, made notable effort to increase the representation from developing countries. Also, if one looks at the five assessment reports, it is evident 
that the first report focused on physical science and economics with climate change mostly perceived as a mitigation issue. The second assessment then widened a bit the scope to bring in issues of development and adaptation. The third report brought in equity consideration while the AR4 brought the emphasis on sustainable development and tried to balance mitigation consideration with adaptation. Despite these laudable objectives, the IPCC however, the IPCC continues to attract harsh criticism. This is in part because beyond increasing participation of developing countries in assessment cycles; there has been very little discussion of exactly what procedural fairness in IPCC looks like and how such state of affairs might be obtained.

\section{A model for evaluating procedural justice in the IPCC}

If a robust case can be made for procedural justice in the IPCC, outlining exactly how a fair system should look like is not a simple matter. With its mandate to produce scientifically rigorous, comprehensive, objective and balanced reviews that are politically relevant, the IPCC is a hybrid organization which has to reconcile the requirement of scientific integrity with political demands for fairness, geopolitical representation and public accountability. For example, the purist of comprehensiveness (through, say, massively increasing the number of authors and widening the sectors and academic subject disciplines covered) may, after a threshold, weigh against the depth and rigour of the assessments. At the same time, a drive for balance could in some circumstances temper the urgency and salience of an argument or a report. The essential challenge is to explicate a procedural justice model that enhances the ability of the IPCC to achieve the multiple, complex and potentially conflicting objectives for which it was set up. To be useful, such a procedural justice model should not be too abstract or philosophical. It should rather attempt to specify what exactly constitutes a fair and just IPCC process and how such justice-enhancing procedures may be operationalized.

Given the paucity of material that concretely analyse procedural justice in environmental politics [Grasso and Sacchi (2015) is a notable exception], I turn to scholarship on social psychology and legal procedures, the combination of which provides extensive insight on what constitutes a fair procedure under varying circumstances. Within this body of literature, the work of Thibaut and Walker (1975) is often taken as the most important starting point. Drawing from extensive work in criminal justice proceedings, Thibaut and Walker (1975) suggested that "process control," or a perception of having some role in the unfolding criminal justice events, was the most important factor shaping perceptions of procedural justice (Ibid 1975: 452). Folger (1977) introduced the concept of "voice," which he defines as the sense people have that their concerns or voice have been heard and considered in the process. He stressed the need to differentiate between participation as involvement ("tokenism") and participation as playing an essential role in deciding the functioning and outcome of the process ("control") (Cf. Gallagher 2008; Prokopy 2004). He noted that while the two dimensions of "voice" are essential for procedural justice, the latter is of more significant consequence.

In his seminal contribution on Fairness in International Law and Institution, Franck (1995) stresses the need to distinguish between fairness in the rules of participation and "background fairness," where the emphasis is on making sure that all parties have equal opportunity and capability to participate under the set rules. In the context of North-South procedural justice in the IPCC, this would suggest that attention needs to go beyond narrow rules of IPCC process and encompass broader structures that engender global inequalities and in particular that 
inhibit the scientific capability and development of developing countries. Leventhal (1980) has sought to provide a fuller framework for procedural justice and the list of factors that make for a fair process. Building on the works of Thibaut and Walker (1975) and Folger (1977), he developed a list of six (6) criteria for procedural justice: (1) consistency of rules and how they are applied, accuracy of information and their interpretation, (2) absence of bias and prejudice, (3) adhering to professional ethics and widely accepted standards of conduct, (4) flexibility to correct if error occurs, and (5) representation of all affected parties involved in the decisionmaking process. Like Thibaut and Walker (1975), before him, Levethan gives considerable weight to process control or having a say in the decision-making process.

Building on previous works, Tyler and Lind (1992) proposed a framework for procedural justice which emphasizes the social-emotional dimensions of procedural fairness. They argue that in addition to formal rules of procedure designed mainly to guarantee representation (involvement) and voice (impact), interactional and relational factors such as status recognition and trust are also essential. In fact, some authors (Bies 2005; Cropanzano et al. 2002; Tyler and Bies 1990) have gone as far as suggesting that "interactional justice" as a distinct concept, to capture the separateness and significance of relational dimensions of group interactions in shaping perceptions of fairness and deciding outcomes. They argue that people's perception of whether they have been treated with dignity often matter more than the quality of decision making rules in their evaluation of procedural fairness. The quality of the social environment has also been found to influence the sense of esteem, trust, cooperation and the outcome of group processes (Schroth and Pradhan Shah 2000; Volmer 2015; Wiesenfeld et al. 2007). A common trend is now to distinguish factors that enhance the quality of decision-making procedure and quality of the interactional environment as two separate but related dimensions of procedural fairness. Accordingly, in judging procedural fairness in the IPCC one needs to pay attention not simply to balance in representation, measured in number of developing country authors, for example, but also to the internal rules of engagement as well as the social and interactional environment in the IPCC in which they, and indeed all authors, operate.

More recently, Tyler and Blader (2003) have proposed a "four-component model of procedural justice" which combines these two dimensions - quality of decision-making procedure and quality of interactional environment - to establish four distinct criteria for judging the fairness of procedures. The first is an evaluation of the quality of formal rules and policies related to how decisions are made in the group. The second is an evaluation of the informal quality of decision-making procedures, which concerns how individuals and groups in authorities actually make decisions. This acknowledges that there is often significant latitude with which formal rules can be interpreted and implemented by those in authority. It also recognizes that there is often a diverse range of situations in any given procedure that formal rules may not cover, leaving those in authority to exercise their discretion. The third criterion is the formal quality of treatment, which refers to the existence and nature of the official rules that prescribe how members should be treated. The fourth is the informal quality of treatment, which refers to how individuals and particular group authorities actually treat group members. It is important to note that while these dimensions are distinct; they are not necessarily independent.

While Tyler and Blader's (2003) four-component procedural justice model offers useful inspiration for generating a framework for procedural fairness in the IPCC, the categories do not match perfectly. The four-component model reflects the focus of the authors on conflict management and legal procedures, where questions about who participates in the process are more or less settled or taken for granted. Furthermore, while the authors would accept that a focus on structural aspects of the decision making environment (nature of courtroom, seating 
arrangements, etc.) matter, the four-component model lumps them all together under formal quality of decision-making rules in a manner that is unhelpful for analysing the IPCC process.

For the sake of analysing procedural justice in the IPCC, I propose, therefore, to separate formal quality of decision-making rules into three distinct categories: (1) rules about representation and participation, (2) rules about governance and management structure, and (3) rules relating to the decision-making processes that directly concern data gathering and report writing. A context-specific model for evaluating procedural fairness in the IPCC process can, therefore, be presented as follows (Fig. 3):

As indicated, the model proposes four separate categories of formal rules and two groups of informal practices (interactional environment) to evaluate the quality of IPCC procedural fairness in IPCC:

(1) Formal rules about representation and participation in IPCC reports - [Representation and Participation Rules]. This covers rules about the selection of authors and also crucially in what capacity selected authors participate. It is about ensuring balanced participation from all constituencies but also that participants from, say, developing countries hold positions of authority.

(2) Formal rules about bureau membership, working group leadership, and TSU location, leadership, membership, and functions-[Governance Structures]. It is becoming clearer that through their roles in nominating authors, providing secretarial support and overseeing the scientific quality of the IPCC work among other strategic functions, these

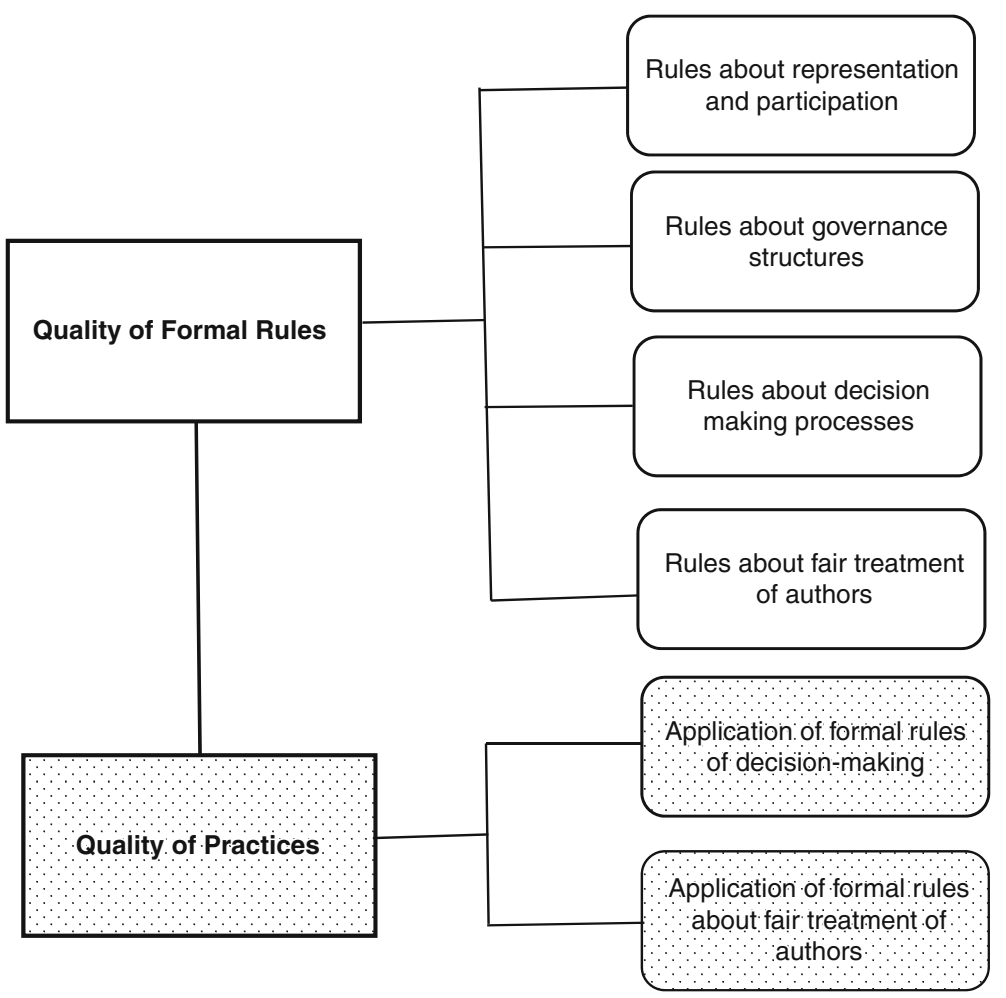

Fig. 3 Framework for evaluating procedural fairness in IPCC 
"hidden" management structures wield a lot of strategic and symbolic power (see Hughes 2015; Hughes and Paterson 2017). Therefore, fairness in representation needs to go beyond IPCC authorship and encompass rules about the composition, roles and functions of these management structures.

(3) Formal rules relating to decision making processes-[Decision Making Rules]. For example, analysis of fair procedure should encompass assessment of what constitutes acceptable evidence or knowledge, how evidence and knowledge are gathered and interpreted, how discrepancies are handled, timing and language of meetings among other such decision-making processes.

(4) Formal rules that relate to fair treatment of authors and other actors in the IPCC process-[Fair Treatment Rules]. These include rules about how debates and discussions are organized to ensure respect, dignity and high quality of cooperation among IPCC authors. Fair treatment rules should be geared towards providing the environment where less assured or vocal panel members (junior, first time, and developing country authors), would feel respected and secure to voice their opinions.

(5) How decision-making rules are interpreted and applied by those in authority-[Application of Decision-Making Rules]. Rules can be robust on paper, but their interpretations can be weak, subjective and biased. This category encompasses how those in authority, say by WG leaders, Bureau members, TSU, CLAs and other groups of authority in the IPCC process conduct themselves and interpret laid out rules. Examples include how they define and seek to achieve consensus among authors.

(6) How respect and trust engendering rules are interpreted and applied by those in authority-[Interactional Environment]. This refers to the application of fair treatment rules by groups of authority. This covers how rules related to respect, trust, rights, recognition, and dignity, are interpreted and applied by groups of authority (e.g. WG leaders, Bureau members, TSU, and CLAs) in formal and crucially informal setting in the IPCC process. For example the effort they make to accommodate less vocal or less confident authors.

It is important to note that these categories can overlap more or less considerably. Level of technical capabilities can help to alter the social dynamics, and by implication, the effect of informal cultural practices. An increase in the absolute number of representatives is likely (but not guaranteed) to result to increase in available technical capacity. The shape and structure of meetings can affect the impact of decision making rules as well as informal practices. Nonetheless, a key insight from the preceding sections is that procedural justice in the IPCC demands not simply increases in representation but also procedural arrangements that ensure quality participation, adequate recognition, voice and control.

\section{Discussion and conclusion}

As a scientific, if an intergovernmental organization, the foremost mandate of the IPCC is to produce sound and comprehensive scientific assessments to guide global climate policy. However, I have argued that procedural justice analysis is warranted in the IPCC for several reasons, including the following: (a) their reports have distributive implications, indirectly through their influence on climate policy; (b) procedural fairness can help achieve the stated objective of producing comprehensive, objective and balanced assessments; (c) perception of procedural fairness will help increase the legitimacy of the IPCC and its reports especially 
since important constituencies which the IPCC reports are supposed to serve continue to feel disenfranchised and marginalized in the process; and (d) the IPCC work is a social process in which procedural justice has independent, intrinsic value that is not linked to its influence over outcome.

Crucially, the paper has proposed a heuristic framework with distinct but closely connected categories through which procedural fairness in the IPCC could be conceptualized and systematically assessed. Methodical assessment will help, on the one hand, to limit inarticulate criticism of the IPCC on the basis of fairness, and on the other hand, to probe, identify and tackle persisting unfair rules and procedures.

One vital contribution of the framework, I hope, is that it highlights the importance of institutional structures and the informal quality of the environment as core procedural justice domains in the IPCC process. Hence, while increasing representation of developing country authors, which has been the mainstay of existing relevant literature, remains an important point, it will be vital, going forward, to pay closer attention to the procedural fairness of the existing IPCC structures and the quality of the interactional environment within which global assessments are undertaken. Creating and emphasizing formal rules that relate to fair treatment of authors, fair structures, and high quality of interactional environment will help to counteract bias and negative influence from groups and networks of authority, which existing literature show is dominated by developed countries (Corbera et al. 2016; Hughes 2015; Hughes and Paterson 2017). Moreover, by increasing the quality of debates, a fair interactional environment could also help to enhance the deliberative quality of the IPCC process and address some the criticisms regarding how the rules of decision by consensus are applied. At the same time, attention to procedural fairness can help to limit the inherent bias towards positivist interpretation and epistemologies (Skodvin 2000; Beck 2012).

Having created the six categories through which to break down the IPCC as an institution into components for evaluation, the operationalization of the framework can take at least one of two forms. The one is a more interpretivist assessment based on the literature and possibly combined with anecdotal evidence from IPCC authors. A type of this assessment is in fact already underway. The other is a more extensive, perhaps quantitative empirical assessment that involves a large survey of IPCC authors, Bureau members, and TSU staff. Such a study could analyse and compare the perception of the quality of the interactional environment of the IPCC based on different demography and roles of the IPCC authors. Another area of inquiry would be to determine the individual and relative significance of the categories as well as how they interact in real life to shape the work of the IPCC and their outputs. I call on scholars to consider undertaking these assessments.

Although the framework has been developed with the IPCC in mind, it has potential to be utilized when evaluating procedural fairness in other regional and global scientific assessment bodies, such as the IPBES Global Assessment of Biodiversity and Ecosystem Services, as well as in the analysis of broader international negotiations involving developed and the developing countries. It should be noted, however, that the model does not engage with the broader question of recognition justice and the fairness (or otherwise) of organizing participation in the IPCC process essentially around states to the exclusion of indigenous population. Moreover, with the categories to assess the IPCC identified, it should not be expected that analysis utilizing the above framework will necessarily yield objective, incontrovertible results since perception of fairness (especially the quality of interactional environment - categories 5 and 6 in the model), can be notoriously subjective. Finally, I would like to stress that given its role as a scientific assessment body, procedural fairness in IPCC is necessary only to the extent that it 
helps to achieve, or at least does not undermine the aim of doing good science. For example "pure proceduralism" (Rawls 1971) which may require that countries are represented by an equal number of authors with less regard paid to claims of skills and expertise would hardly be a defensible proposition since such a process can scarcely lead to the outcome of a robust assessment. However, since there will always be an abiding indeterminacy about what exactly constitutes objective, balanced and comprehensive scientific assessment, and who gets to judge when an IPCC report meets these criteria (Edwards and Schneider 2001; Holland 2007; Shackley and Skodvin 1995), a focus on defining, clarifying and enhancing procedural fairness will remain vital for improving the work of the IPCC and, increasing the legitimacy of its reports.

Acknowledgements I would like to acknowledge the following colleagues for your helpful suggestions and comments on previous drafts of the manuscripts: Simon Caney, Mathew Paterson, Youba Sokona, Dominic Roser, Silke Beck, Hannah Hughes, and Philip Coventry.

Open Access This article is distributed under the terms of the Creative Commons Attribution 4.0 International License (http://creativecommons.org/licenses/by/4.0/), which permits unrestricted use, distribution, and reproduction in any medium, provided you give appropriate credit to the original author(s) and the source, provide a link to the Creative Commons license, and indicate if changes were made.

\section{References}

Agrawala S (1998a) Context and early origins of the Intergovernmental Panel on Climate Change. Clim Chang 39(4):605-620

Agrawala S (1998b) Structural and process history of the Intergovernmental Panel on Climate Change. Clim Chang 39(4):621-642

Alexander S, Ruderman M (1987) The role of procedural and distributive justice in organizational behavior. Soc Justice Res 1(2):177-198

Beck S (2011) Moving beyond the linear model of expertise? IPCC and the test of adaptation. Reg Environ Chang 11(2):297-306

Beck S (2012) Between tribalism and trust: the IPCC under the "public microscope". Nature and Culture 7(2): $151-173$

Biermann F (2001) Big science, small impacts - in the South? The influence of global environmental assessments on expert communities in India. Glob Environ Chang 11(4):297-309

Biermann F, Gupta A (2011) Accountability and legitimacy in earth system governance: a research framework. Ecol Econ 70(11):1856-1864

Bies RJ (2005) Are procedural justice and interactional justice conceptually distinct? In: Greenberg J, Colquitt JA (eds) Handbook of organizational justice. Lawrence Erlbaum Associates Publishers, Mahwah, pp 85-112 xxvi, $647 \mathrm{pp}$

Bjurström A, Polk M (2011a) Climate change and interdisciplinarity: a co-citation analysis of IPCC Third Assessment Report. Scientometrics 87(3):525-550

Bjurström A, Polk M (2011b) Physical and economic bias in climate change research: a scientometric study of IPCC Third Assessment Report. Clim Chang 108(1):1-22

Bodansky D (1993) The United Nations framework convention on climate change: a commentary. Yale J Int'l 1 $18: 451$

Bradford B, Huq A, Jackson J, Roberts B (2014) What price fairness when security is at stake? Police legitimacy in South Africa. Regulation \& governance 8(2):246-268

Brown MJ, Havstad JC (2017) The disconnect problem, scientific authority, and climate policy. Perspect Sci 25(1):67-94

Corbera E, Calvet-Mir L, Hughes H, Paterson M (2016) Patterns of authorship in the IPCC Working Group III report. Nat Clim Chang 6(1):94-99

Cropanzano R, Prehar CA, Chen PY (2002) Using social exchange theory to distinguish procedural from interactional justice. Group \& Organization Management 27(3):324-351

De Cremer D, Tyler TR (2005) Managing group behavior: the interplay between procedural justice, sense of self, and cooperation. Adv Exp Soc Psychol 37:151-218 
Devès MH, Lang M, Bourrelier PH, Valérian F (2017) Why the IPCC should evolve in response to the UNFCCC bottom-up strategy adopted in Paris? An opinion from the French Association for Disaster Risk Reduction. Environ Sci Pol 78:142-148

Edwards PN, Schneider SH (2001) Self-governance and peer review in science-for-policy: the case of the IPCC Second Assessment Report. In: Miller CA, Edwards P (eds) Changing the atmosphere: expert knowledge and environmental governance. MIT Press, Cambridge, London, pp 219-246

Folger R (1977) Distributive and procedural justice: combined impact of "voice" and improvement on experienced inequity. J Pers Soc Psychol 35(2):108-119

Ford JD, Vanderbilt W, Berrang-Ford L (2012) Authorship in IPCC AR5 and its implications for content: climate change and indigenous populations in WGII. Clim Chang 113(2):201-213

Ford JD, Cameron L, Rubis J, Maillet M, Nakashima D, Willox AC, Pearce T (2016) Including indigenous knowledge and experience in IPCC assessment reports. Nat Clim Chang 6(4):349-353

Fløttum K, Gasper D, Clair ALS (2016) Synthesizing a policy-relevant perspective from the three IPCC "worlds"- a comparison of topics and frames in the SPMs of the fifth assessment report. Glob Environ Chang 38:118-129

Franck TM (1995) Fairness in international law and institutions. Oxford University Press, Oxford

Gallagher M (2008) Foucault, power and participation. The. Int J Childr Rights 16(3):395-406

Grasso M, Sacchi S (2015) Impure procedural justice in climate governance systems. Environmental Values 24(6):777-798

Hajer MA (2012) A media storm in the world risk society: enacting scientific authority in the IPCC controversy (2009-10). Critical Policy Studies 6(4):452-464

Holland D (2007) Bias and concealment in the IPCC process: the "hockey-stick" affair and its implications. Energy Environ 18(7):951-983

Hughes H (2015) Bourdieu and the IPCC's symbolic power. Glob Environ Politics

Hughes HR, Paterson M (2017) Narrowing the climate field: the symbolic power of authors in the IPCC's assessment of mitigation. Review of Policy Research. http://onlinelibrary.wiley.com/doi/10.1111/ropr.12255/full/

Hulme M, Mahony M (2010) Climate change: what do we know about the IPCC? Prog Phys Geogr 34(5):705718

Khanna N, Chapman D (1996) Time preference, abatement costs, and international climate policy: an appraisal of IPCC 1995. Contemp Econ Policy 14(2):56

Leventhal GS (1980) What should be done with equity theory? In Social exchange. Springer, US, p 27-55

Levi M, Sacks A (2009) Legitimating beliefs: sources and indicators. Regulation \& Governance 3(4):311-333

Liu C, Pan J, Chen Y, Chen M (2014) Countries' historical emission responsibilities: a normative perspective. Chinese Journal of Urban and Environmental Studies 2(02):1450018

Mach KJ, Mastrandrea MD, Freeman PT, Field CB (2017) Unleashing expert judgment in assessment. Glob Environ Chang 44:1-14

Murphy K (2005) Regulating more effectively: the relationship between procedural justice, legitimacy, and tax non-compliance. J Law Soc 32(4):562-589

Najam A, Rahman AA, Huq S, Sokona Y (2003) Integrating sustainable development into the fourth assessment report of the Intergovernmental Panel on Climate Change. Clim Pol 3(sup1):S9-S17

Obermeister N (2017) From dichotomy to duality: addressing interdisciplinary epistemological barriers to inclusive knowledge governance in global environmental assessments. Environ Sci Pol 68:80-86

Okereke C (2007) Global justice and neoliberal environmental governance: ethics, sustainable development and international co-operation. Routledge, London, Abingdon

Okereke C (2010) Climate justice and the international regime. Wiley Interdiscip Rev Clim Chang 1(3):462-474

Pasgaard M, Dalsgaard B, Maruyama PK, Sandel B, Strange N (2015) Geographical imbalances and divides in the scientific production of climate change knowledge. Glob Environ Chang 35:279-288

Prokopy LS (2004) Women's participation in rural water supply projects in India: is it moving beyond tokenism and does it matter? Water Policy 6(2):103-116

Pielke RA Jr (2010) Major change is needed if the IPCC hopes to survive. Yale Environment 360:25

Rawls J (1971) A theory of justice. Harvard University Press, London

Schroth HA, Pradhan Shah P (2000) Procedures: do we really want to know them? An examination of the effects of procedural justice on self-esteem. J Appl Psychol 85(3):462

Shackley S, Skodvin T (1995) IPCC gazing and the interpretative social sciences: a comment on Sonja BoehmerChristiansen's: "global climate protection policy: the limits of scientific advice". Glob Environ Chang 5(3): $175-180$

Siebenhüner B (2002) How do scientific assessments learn?: part 1. Conceptual framework and case study of the IPCC. Environ Sci Pol 5(5):411-420

Skodvin T (2000) Revised rules of procedure for the IPCC process. Clim Chang 46(4):409-415

Stocker TF, Plattner G-K (2014) Climate policy: rethink IPCC reports. Comm Nat 513:163-165 
Thibaut J, Walker L (1975) Procedural justice: a psychological analysis. Erlbaum, Hillsdale

Tomlinson L (2015) Procedural justice in the United Nations Framework Convention on Climate Change. Springer International Publishing Press, Switzerland and London

Tyler TR, Bies RJ (1990) Beyond formal procedures: the interpersonal context of procedural justice. Appl. Soc. Psychol. Organ. Settings 77:98

Tyler TR, Blader SL (2000) Cooperation in groups: procedural justice, social identity, and behavioral engagement. Physchology Press, New York

Tyler TR, Blader SL (2003) The group engagement model: procedural justice, social identity, and cooperative behavior. Personal Soc Psychol Rev 7(4):349-361

Tyler TR, Caine A (1981) The influence of outcomes and procedures on satisfaction with formal leaders. J Pers Soc Psychol 41(4):642

Tyler TR, Lind EA (1992) A relational model of authority in groups. Adv Exp Soc Psychol 25:115-191

Vardy M, Oppenheimer M, Dubash NK, O'Reilly J, Jamieson D (2017) The intergovernmental panel on climate change: a history and review. Annu Rev Environ Resour 42(1):55-75

Volmer J (2015) Followers' daily reactions to social conflicts with supervisors: the moderating role of core selfevaluations and procedural justice perceptions. Leadersh Q 26(5):719-731

Wiesenfeld BM, Swann WB, Brockner J, Bartel CA (2007) Is more fairness always preferred? Self-esteem moderates reactions to procedural justice. Acad Manag J 50(5):1235-1253

Yang J, Mossholder KW, Peng TK (2009) Supervisory procedural justice effects: the mediating roles of cognitive and affective trust. Leadersh Q 20(2):143-154

Yohe G, Oppenheimer M (2011) Evaluation, characterization, and communication of uncertainty by the intergovernmental panel on climate change — an introductory essay. Clim Chang 108(4):629 